\title{
Hot isostatic pressing assisted diffusion bonding for application to the Super Proton Synchrotron internal beam dump at CERN
}

\author{
S. Pianese $\odot,{ }^{1, *}$ A. Perillo Marcone,${ }^{1, \dagger}$ F.-X. Nuiry $\odot,{ }^{1}$ M. Calviani $\odot,{ }^{1,+}$ K. Adam Szczurek $\odot,{ }^{1}$ \\ G. Arnau Izquierdo, ${ }^{1}$ P. Avigni, ${ }^{1}$ S. Bonnin $\odot,{ }^{1}$ J. Busom Descarrega, ${ }^{1}$ T. Feniet, ${ }^{1}$ K. Kershaw, ${ }^{1}$ \\ J. Lendaro, ${ }^{1}$ A. Perez Fontenla, ${ }^{1}$ T. Schubert, ${ }^{2}$ S. Sgobba $\odot,{ }^{1}$ and T. Weißgärber ${ }^{2}$ \\ ${ }^{1}$ CERN, 1211 Geneva 23, Switzerland \\ ${ }^{2}$ IFAM, Winterbergstrasse 28, 01277 Dresden, Germany
}

(Received 17 November 2020; accepted 9 March 2021; published 14 April 2021)

\begin{abstract}
The new generation internal beam dump of the Super Proton Synchrotron (SPS) at CERN will have to dissipate approximately $270 \mathrm{~kW}$ of thermal power, deposited by the primary proton beam. For this purpose, it is essential that the cooling system features a very efficient heat evacuation. Diffusion bonding assisted by hot isostatic pressing (HIP) was identified as a promising method of joining the cooling circuits and the materials of the dumps core in order to maximize the heat transfer efficiency. This paper presents the investigation of HIP assisted diffusion bonding between two $\mathrm{CuCr} 1 \mathrm{Zr}$ blanks enclosing SS 316 tubes and the realization of a real size prototype of one of the dump's cooling plates, as well as the assessments of its cooling performance under the dump's most critical operational scenarios. Energy-dispersive x-ray spectroscopy, microstructural analyses, measurements of thermal conductivity, and mechanical strength were performed to characterize the HIP diffusion bonded interfaces $(\mathrm{CuCr} 1 \mathrm{Zr}-\mathrm{CuCr} 1 \mathrm{Zr}$ and $\mathrm{CuCr} 1 \mathrm{Zr}-\mathrm{SS}$ 316L). A test bench allowed to assess the cooling performance of the real size prototype. At the bonded interface, the presence of typical diffusional phenomena was observed. Moreover, measured tensile strength and thermal conductivity were at least equivalent to the lowest ones of the materials assembled and comparable to its bulk properties, meaning that a good bonding quality was achieved. Finally, the real size prototype was successfully tested with an ad hoc thermal test bench and with the highest operational thermal power expected in the new generation SPS internal beam dump. These results demonstrated the possibility to use HIP as a manufacturing technique for the cooling plates of the new generation SPS internal beam dump, but they also open up the way for further investigations on its exploitability to improve the cooling performance of any future high intensity beam intercepting device or in general devices requiring very efficient heat evacuation systems.
\end{abstract}

DOI: 10.1103/PhysRevAccelBeams.24.043001

\section{INTRODUCTION}

The new generation internal beam dump (Target Internal Dump Vertical Graphite, TIDVG\#5 [1]) of the Super Proton Synchrotron (SPS) at CERN, built in the framework of the Large Hadron Collider (LHC) Injectors Upgrade (LIU) Project [2] has been installed in the long straight section 5 (LSS5) of the SPS during the CERN's Long Shutdown 2 (LS2), 2019-2020. Higher beam intensities and energies, resulting from the LIU upgrades, are making the cooling of

\footnotetext{
*stefano.pianese@cern.ch

antonio.perillo-marcone@cern.ch

Corresponding author.

marco.calviani@cern.ch
}

Published by the American Physical Society under the terms of the Creative Commons Attribution 4.0 International license. Further distribution of this work must maintain attribution to the author(s) and the published article's title, journal citation, and DOI. this device, and in general of most beam intercepting devices (BIDs) at CERN, increasingly demanding. A key problem is obtaining high levels of heat transfer efficiency between the core beam absorbing materials and the cooling circuits. Specifically, the SPS internal beam dump is required to evacuate a maximum average beam thermal power of approximately $270 \mathrm{~kW}$, more than 4 times the limit of its predecessor TIDVG\#4 [3]. As shown in Fig. 1, the core of the SPS internal dump is made of an array of absorbing blocks consisting in $4.4 \mathrm{~m}$ of isostatic graphite, $0.2 \mathrm{~m}$ of TZM, and $\sim 0.4 \mathrm{~m}$ of pure tungsten, enclosed within $2.5 \mathrm{~m}$ long $\mathrm{CuCr} 1 \mathrm{Zr}$ cooling plates and under ultrahigh vacuum conditions (UHV). Whenever high energy proton beams need to be dumped (i.e. in case of emergency, during LHC beam setup or LHC filling, machine developments and to dispose of the part of the beam for fixed targets remaining after the slow-extraction process), they are deflected onto the absorbing blocks by an upstream set of three vertical and three horizontal kickers. 
The $\mathrm{CuCr} 1 \mathrm{Zr}$ cooling plates must dissipate most of the thermal power carried by the proton beam and diffused by conduction from the absorbing blocks to the $\mathrm{CuCr} 1 \mathrm{Zr}$ heat sinks. As a consequence, their heat evacuation efficiency is crucial for the survivability of the absorber system.

In the previous generation device [4], the $\mathrm{CuCr} 1 \mathrm{Zr}$ plates were mechanically clamping stainless steel tubes. However, interfaces play a major role in the heat evacuation mechanism, as they represent a resistance to the heat transfer. For this reason, a possible way to obtain the highest possible thermal contact conductance was identified by means of diffusion bonding. Hot isostatic pressing (HIP) assisted diffusion bonding was previously identified as a promising joining technique between copper alloys and stainless steel [5]; by combining elevated temperatures (up to $2000{ }^{\circ} \mathrm{C}$ ) and isostatic gas pressure (up to $200 \mathrm{MPa}$ ), HIP is mainly used to heal casting or additive manufacturing defects and for powder metallurgy parts consolidations [6-8].

Diffusion bonding via HIP has been extensively studied as a joining technique for several materials [9-11], especially for fusion energy applications [10,12-14] including damage from neutron irradiation.

Nevertheless, it has not been used so far to manufacture diffusion bonding large cooling plates for UHV applications. The core of the new generation SPS beam dump is $5 \mathrm{~m}$ long, but, given the maximum dimensions of HIP ovens available, the HIPed cooling plates were divided into four parts of $2.5 \mathrm{~m}$ each: two bottom upstream/downstream and two top upstream/downstream (Fig. 1). The objective of this work was to characterize the HIP diffusion-bonded interfaces between $\mathrm{CuCr} 1 \mathrm{Zr}$ and $\mathrm{SS} 316 \mathrm{~L}$, as well as between $\mathrm{CuCr} 1 \mathrm{Zr}$ and $\mathrm{CuCr} 1 \mathrm{Zr}$, and to assess the cooling performance of a real size prototype of cooling plate under the dump's most critical operational scenario.

The use of HIPing to diffusion bond $\mathrm{CuCr} 1 \mathrm{Zr}$ with SS316L has also been used with success for the CERN PS internal dump [15] as well as for the beam dump facility target prototype beam test [16] to diffusion bond dissimilar refractory metals. Because of increasingly demanding particle beams, this manufacturing technique could be of

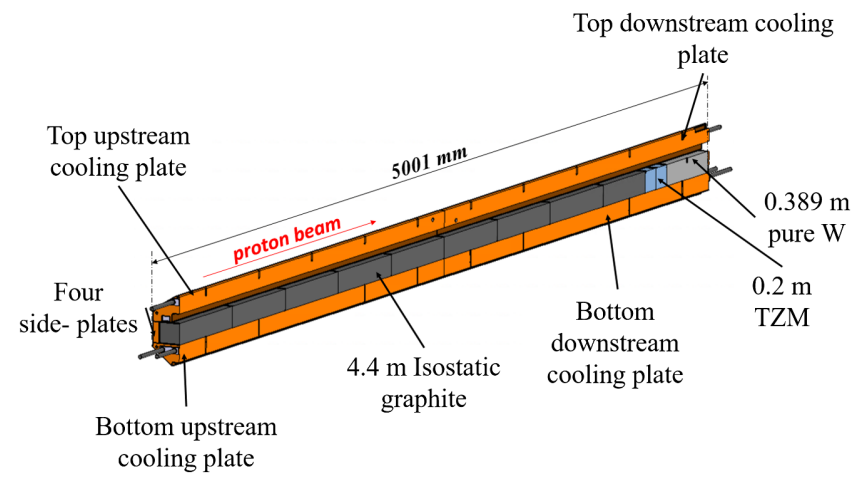

FIG. 1. Cross section of the new generation SPS internal dump core, TIDVG\#5. interest to improve the cooling performances of many other BIDs such as the new ISOLDE beam dumps, planned to be refurbished by 2025 within the scope of the EPIC Project [17], the new $30 \mathrm{~kW}$ beam dump of the J-PARC main ring [18], as well as absorbing devices within the Proton Improvement Plan-II Project [19] at FNAL, the International Linear Collider (ILC) photon dumps or in general any other device requiring very efficient heat evacuation systems.

Radiation damage of the interface is not expected to be a limiting factor for this device, being relatively far from the area directly impacted by the proton beam and the resulting shower. Information about similar bonding performances under neutron irradiation was, for example, studied in Ref. [13].

\section{METHODOLOGY}

The components needed for a real size cooling plate prototype were manufactured, assembled at CERN and diffusion bonded by a HIP cycle. A subpart of the prototype was cut and used to manufacture samples to characterize the diffusion bonded interfaces by means of microstructural analyses, energy-dispersive x-ray (EDX) spectroscopy, and measurements of thermal conductivity and mechanical strength. Measurements of electrical conductivity and Brinell hardness were performed on the bulk of $\mathrm{CuCr} 1 \mathrm{Zr}$ to quantify the evolution of these properties after the HIP cycle and the following thermal treatments. The rest of the prototype was used within a built-in-house test bench to assess its cooling performance under the dump's most critical operational scenario.

\section{A. Materials}

The prototype to be assembled by HIP diffusion bonding (Fig. 2) consisted of two precipitation hardened $\mathrm{CuCr} 1 \mathrm{Zr}$ blanks from ZOLLERN GMBH (Germany), $2.7 \mathrm{~m}$ long, embedding in a sandwich two U-bent SS 316L (EN 1.4435) tubes. Tables I and II show the chemical composition of this copper alloy and the SS 316L, respectively. The SS 316L

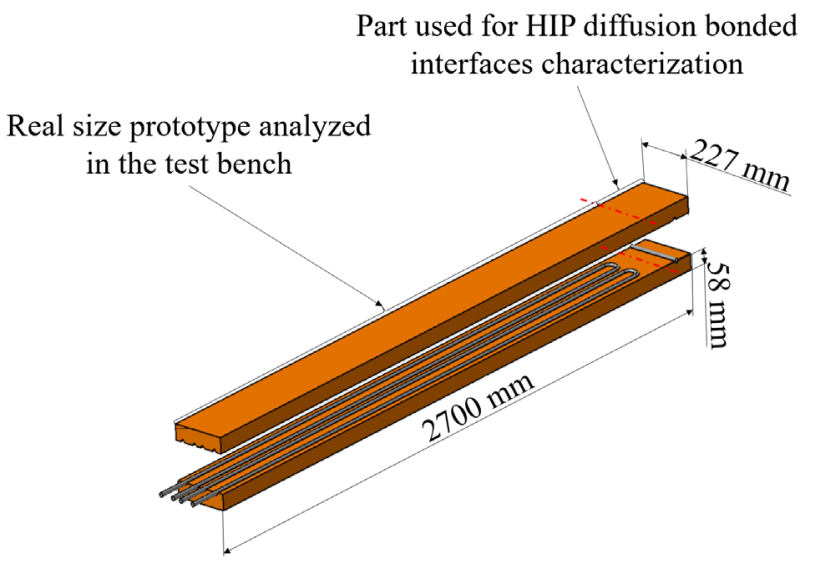

FIG. 2. Design details of the real size cooling plate prototype. 
TABLE I. CuCr1Zr chemical composition [wt \%] and material designation according to EN 12420 and product analysis.

\begin{tabular}{|c|c|c|c|c|c|c|c|c|c|}
\hline \multicolumn{3}{|c|}{ Material designation } & \multirow{2}{*}{$\frac{\text { Element }}{\text { Min/max }}$} & \multirow{2}{*}{$\begin{array}{l}\mathrm{Cu} \\
\text { Rem- } \\
\text { Rem }\end{array}$} & \multirow{2}{*}{$\begin{array}{c}\mathrm{Cr} \\
0.5 / 1.2 \\
0.8\end{array}$} & \multirow{2}{*}{$\begin{array}{c}\mathrm{Fe} \\
-/ 0.8 \\
<0.01\end{array}$} & \multirow{2}{*}{$\begin{array}{c}\mathrm{Si} \\
-/ 0.1 \\
<0.01\end{array}$} & \multirow{2}{*}{$\begin{array}{c}\mathrm{Zr} \\
0.03 / 0.3 \\
0.09\end{array}$} & \multirow{2}{*}{$\begin{array}{c}\text { Others total } \\
-/ 0.2 \\
\ldots\end{array}$} \\
\hline Symbol & $\begin{array}{c}\text { Number } \\
\text { FN. CW106C. UNS. C18150 }\end{array}$ & EN12420 & & & & & & & \\
\hline
\end{tabular}

TABLE II. SS316L chemical composition [wt \%] and material designation according to EN10088-3 and product analysis.

\begin{tabular}{|c|c|c|c|c|c|c|c|c|c|c|c|}
\hline Material designation & & $\mathrm{C}$ & $\mathrm{Si}$ & $\mathrm{Mn}$ & $\mathrm{P}$ & S & $\mathrm{N}$ & $\mathrm{Cr}$ & $\mathrm{Cu}$ & Mo & $\mathrm{Ni}$ \\
\hline \multirow[t]{2}{*}{ AISI 316L } & EN: $10088-3$ & 0.030 & 1.00 & 2.00 & 0.045 & 0.030 & 0.11 & $17.0 / 19.0$ & & $2.50 / 3.00$ & $12.5 / 15.0$ \\
\hline & Product analysis & 0.024 & 0.42 & 1.54 & 0.029 & 0.008 & 0.045 & 17.59 & & 2.56 & 13.08 \\
\hline
\end{tabular}

cooling tubes are cold bent and annealed. The annealing cycle for SS 316L consists in a heating-up phase at $200-300^{\circ} \mathrm{C} / \mathrm{h}$ up to $950^{\circ} \mathrm{C}$, followed by a plateau at this temperature of at least $2 \mathrm{~h}$ and natural cooling down to ambient temperature. The furnace employed was of the type Grand-Four UGINE for thermal treatments under vacuum, manufactured by Alstom in 1974. It has an exploitable inner diameter of $990 \mathrm{~mm}$ for $6000 \mathrm{~mm}$ height and a maximum capacity of $1000 \mathrm{~kg}$. The maximum reachable temperature is $1100^{\circ} \mathrm{C}$ with heating rates ranging from 50 to $300^{\circ} \mathrm{C} / \mathrm{h}$. The cooling is by natural convection to ambient air. The $\mathrm{CuCr} 1 \mathrm{Zr}$ blanks are multidirectionally forged according to the standard EN 12420 and heat treated as described below. References [20,21] indicate that the following thermal treatments sequence, applied on $\mathrm{CuCr} 1 \mathrm{Zr}$, allows to obtain the highest values of electrical and thermal conductivity, hardness, tensile properties, good ductility, and machinability: (1) Solution annealing between $950^{\circ} \mathrm{C}$ and $1000^{\circ} \mathrm{C}$ for $30 \mathrm{~min}$ followed by water quenching. (2) Precipitation hardening through aging at $480-500{ }^{\circ} \mathrm{C}$ for $2 \mathrm{~h}$ and slow cooling in air. Hereinafter in the paper, the material shall be considered to have followed this treatment, and it will be referred to as precipitation hardened $\mathrm{CuCr} 1 \mathrm{Zr}$ or simply $\mathrm{CuCr} 1 \mathrm{Zr}$.

After the HIP cycle, despite the high temperatures, the grains structure does not change, most likely due to the hydrostatic pressure at which the material is exposed during treatment, but the thermal and mechanical properties need to be recovered using the same treatment. Table III shows how electrical conductivity and Brinell hardness, measured on the rear side of the prototype, change after HIP and following the different steps of the heat treatment cycle. For

TABLE III. Electrical conductivity and Brinell hardness evolution with heat treatments after HIP.

\begin{tabular}{lcc}
\hline \hline Heat treatment & Electrical conductivity & Hardness \\
\hline HIP & $41.7 \mathrm{MS} / \mathrm{m}$ & $45 \mathrm{HB}$ \\
$\begin{array}{l}\text { Solution annealing } \\
\text { and water quenching }\end{array}$ & $25 \mathrm{MS} / \mathrm{m}$ & $60 \mathrm{HB}$ \\
Aging & $51 \mathrm{MS} / \mathrm{m}$ & $108 \mathrm{HB}$ \\
\hline \hline
\end{tabular}

this application, thermal conductivity was slightly more important than mechanical strength; therefore, the aging phase was performed closer to the upper limit of $500^{\circ} \mathrm{C}$. Indeed, a higher temperature promotes the precipitation but induces also a slight coarsening of the precipitates, thus lowering the mechanical strength.

\section{B. Prototype design}

Figure 2 shows the overall dimensions of the two precipitation hardened $\mathrm{CuCr} 1 \mathrm{Zr}$ halves assembled with the tubes, corresponding to $227 \mathrm{~mm}(\mathrm{~W}), 116 \mathrm{~mm}(\mathrm{H})$, and $2700 \mathrm{~mm}(\mathrm{~L})$.

The inner and outer diameters of the tubes are 15 and $18 \mathrm{~mm}$, respectively. The rear part of the assembly, containing a straight tube of SS $316 \mathrm{~L}$, is meant to be cut off to be used for the characterization of the bonded interfaces after the HIP cycle and heat treatments. Before the HIPing cycle, to ease as much as possible the diffusion bonding at the interfaces, the parts have been cleaned. The cleaning consists in degreasing the parts by immersion in a solution of a compatible alkaline detergent $(\mathrm{pH} 9.7)$ at $60^{\circ} \mathrm{C}$ for $60 \mathrm{~min}$, while an ultrasonic agitation is set for $10-20 \mathrm{~min}$, and final rinsing with demineralized water followed by drying with clean compressed air or nitrogen.

\section{HIP capsule}

During the HIP cycle, pressure is hydrostatically applied inside the tubes and outside the precipitation hardened $\mathrm{CuCr} 1 \mathrm{Zr}$ blanks. In order to promote diffusion bonding at the component's interfaces, these latter must be kept under vacuum during the HIPing cycle. As shown in Fig. 3, a capsule encloses the assembly and keeps the vacuum leak tightness all over the cycle duration. The HIP capsule is made of six SS 304L plates: the front and rear plates are $8 \mathrm{~mm}$ thick, whereas the rest are $2 \mathrm{~mm}$. The plates are welded together, the lateral and top/bottom by edge welds, while the front and rear by lap welds with the rest of the plates. In order to lower as much as possible the stresses on the welds during the HIP cycle, the capsule dimensions are tailored on the inner $\mathrm{CuCr} 1 \mathrm{Zr} /$ tubes assembly. The eight corners formed by the six SS 304L plates are filled with 


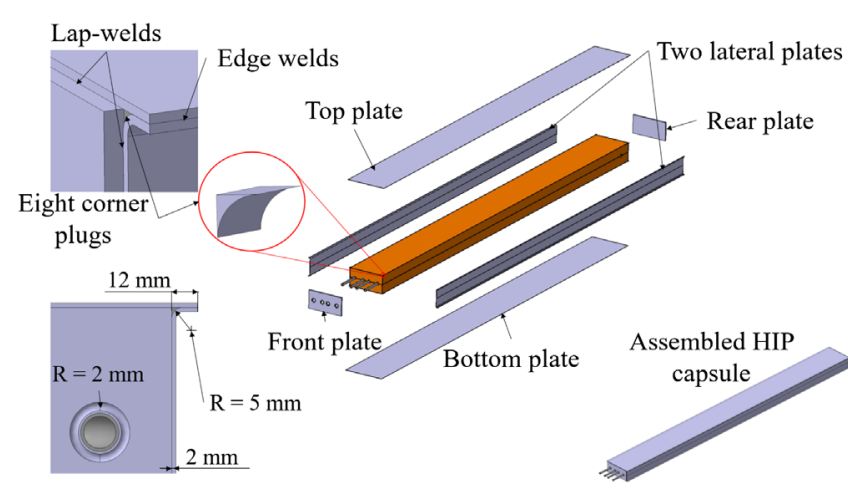

FIG. 3. HIP capsule components and main characteristics.

plugs, which are melted during the welding process making more uniform beads. All the welds of the capsule are tested by dye penetrant and total helium leak test. The dye penetrant tests are performed according to the standard ISO 3452-1-2013, and all the welds should be conformed at least to the acceptance level $2 \times$ of the standard ISO 23277 2009-EN-BS. The penetrant liquid, the developer, and cleaner used are, respectively, Ardrox penetrant 907 PB (red dye), Ardrox 9D1 B, and Ardrox 9 PR 88. The total helium leak test is performed according to the standard EN 1779 and NF EN ISO 20485. The capsule is evacuated and connected to a detector type Leybold L300 or ASM 142 calibrated on helium-4 (the gas tracer). A higher concentration of the gas tracer is created around the capsule by enclosing it in a bag. The leak rate is calculated based on the signal recorded and the helium- 4 concentration inside the bag. The capsule is accepted if there are no leaks within the sensibility of the test, $1 \times 10^{-9} \mathrm{mbar} .1 / \mathrm{s}$.

It is important to reach a good vacuum level (at least $10^{-3}$ mbar) in order to avoid that air pockets remain trapped at the interfaces thus potentially lowering the bonding quality. Before the HIP cycle, the capsule is pumped down by means of the lateral tube shown in Fig. 4. CuCr1Zr, SS 304L, and SS 316L have very similar thermal expansion coefficients within the operational HIP temperatures, ranging from $15 \times 10^{-6} \mathrm{~m} / \mathrm{m} \mathrm{K}^{-1}$ at room

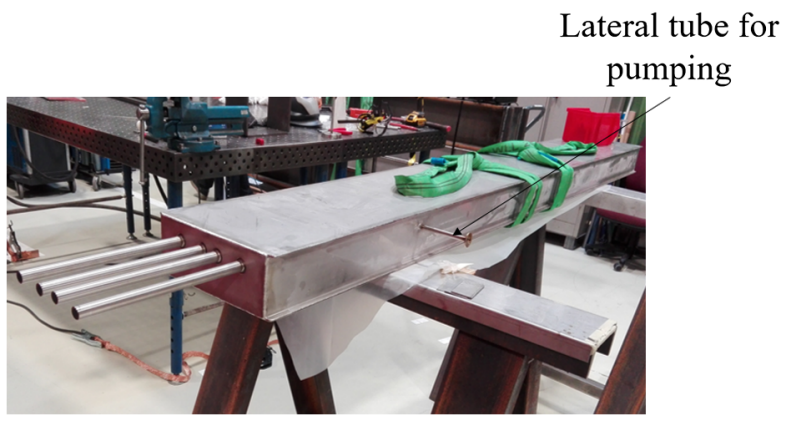

FIG. 4. The HIP capsule containing the CuCr1Zr and tubes assembly, PT and He leak tested with the lateral tube for pumping.
TABLE IV. HIP unit characteristics.

\begin{tabular}{|c|c|c|c|c|c|}
\hline Manufacturer & Model & $\begin{array}{c}\text { Max load } \\
\text { dimensions } \\
{[\mathrm{mm}]}\end{array}$ & $\begin{array}{c}\text { Max } \\
\text { load } \\
\text { weight } \\
{[\mathrm{kg}]}\end{array}$ & $\begin{array}{l}\text { Max } \\
\text { mperature } \\
{[\mathrm{C}]}\end{array}$ & $\begin{array}{c}\text { Max } \\
\text { pressure } \\
{[\mathrm{MPa}]}\end{array}$ \\
\hline ASEA & $\begin{array}{c}\text { QIH307 } \\
\text { "Mega- } \\
\text { HIP" }\end{array}$ & $\begin{array}{l}\phi 1300 \\
h 3200\end{array}$ & 10000 & 1240 & 140 \\
\hline
\end{tabular}

temperature up to almost $20 \times 10^{-6} \mathrm{~m} / \mathrm{m} \mathrm{K}^{-1}$ at $1000^{\circ} \mathrm{C}$ : stresses due to relative thermal expansions and contractions are then limited.

\section{HIPing cycle}

The capsule is transported into a HIP unit: a system applying high pressure with argon gas and high temperature. Table IV shows the main characteristics of the HIP unit used.

As shown in Fig. 5, the HIP cycle phases and the parameters chosen are the following: (1) Phase 1, starting phase: the pressure is raised up to $22.5 \mathrm{MPa}$ and the temperature is kept constant to ambient value (around $50^{\circ} \mathrm{C}$ ). The parameters of this phase might change, as they depend on the specific HIP unit used. (2) Phase 2, heating phase: linear pressure and temperature increase up to $105 \mathrm{MPa}$ and $950^{\circ} \mathrm{C}$. The temperature increases at a rate of $\sim 5^{\circ} \mathrm{C} / \mathrm{min}$. (3) Phase 3, sustaining phase: the following parameters of temperature and pressure are kept over 180 min-temperature: $950{ }^{\circ} \mathrm{C}$ and pressure: $105 \mathrm{MPa}$. (4) Phase 4, cooling phase: pressure and temperature are decreased to ambient value. The temperature decreases by natural cooling at a rate of $\sim 5^{\circ} \mathrm{C} / \mathrm{min}$.

\section{E. Ultrasonic testing examination and capsule opening}

Inspection by ultrasonic testing (UT) is a preliminary and fast method to check if the parts have achieved an intimate

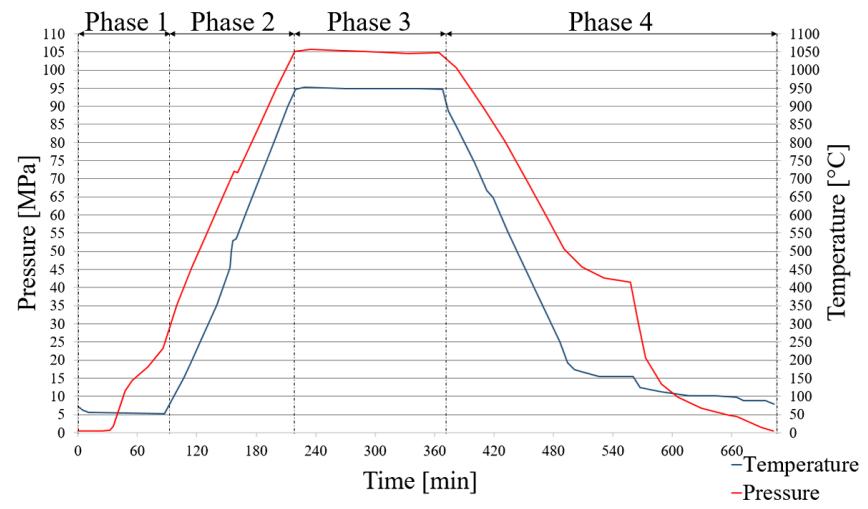

FIG. 5. Temperature and pressure over time of the HIP cycle performed for the prototype of cooling plate of the SPS beam dump. 


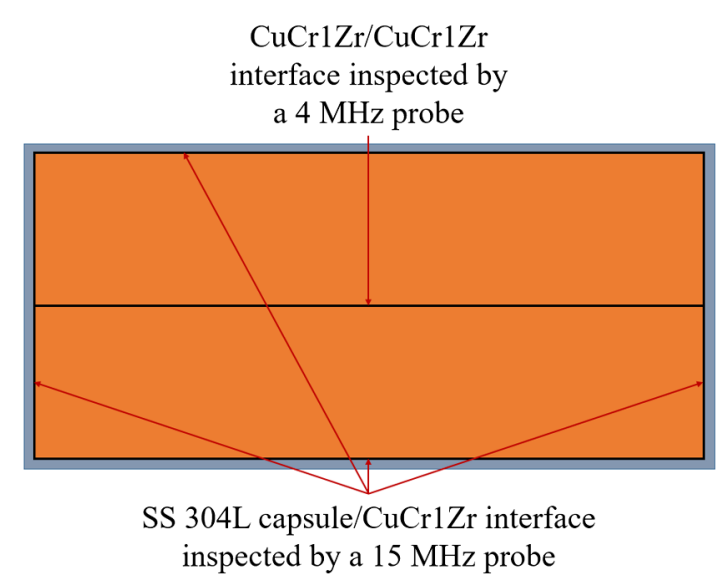

FIG. 6. Interfaces inspected by ultrasounds after HIP cycle.

contact after the HIP cycle. The interfaces that can be easily inspected are the SS $304 \mathrm{~L}$ capsule/CuCr1Zr and $\mathrm{CuCr} 1 \mathrm{Zr} /$ $\mathrm{CuCr} 1 \mathrm{Zr}$ as shown in Fig. 6. If the HIPing process is successful, the different parts of the assembly are in intimate contact and there are very few or no reflections at the interfaces. Specifically, at the interface between the SS 304L capsule and $\mathrm{CuCr} 1 \mathrm{Zr}$, the ultrasound beam will only be reflected in a small portion due to the slight difference in acoustic impedance of the joined materials. This interface was inspected with an ALPHA2, $15 \mathrm{MHz}$ and $6 \mathrm{~mm}$ diameter probe. With a gain of $40 \mathrm{~dB}$ and the speed of sound in stainless steel of $5800 \mathrm{~m} / \mathrm{s}$, the reflection obtained was $<5 \%$. The interface between $\mathrm{CuCr} 1 \mathrm{Zr} /$ $\mathrm{CuCr} 1 \mathrm{Zr}$, given its bigger depth, was inspected with the lower frequency SEB4 probe of $4 \mathrm{MHz}$ and $20 \mathrm{~mm}$ diameter. The only reflection obtained was the back-wall echo corresponding to the thickness of the assembly. This inspection was carried out by setting a gain of $60 \mathrm{~dB}$ and the speed of sound in copper of about $4800 \mathrm{~m} / \mathrm{s}$. The ultrasound beams generator was an USM Go + . The probes and the UT generator were provided by General Electric. After the UT inspections, the capsule was removed by machining.

\section{F. HIP diffusion bonded interface examination}

The interfaces were inspected with optical and electronic microscopes to assess the diffusion bonding quality. The equipment used for the examinations consisted in the following: (1) Digital microscope KEYENCE VHX 6000. (2) Scanning electron microscope, field emission gun FEG Sigma (ZEISS) with InLens (secondary electron), Everhart-Thornley secondary electron (SE2), and backscattered electron (AsB) detectors for imaging. (3) $50 \mathrm{~mm}^{2}$ $\mathrm{X}$ Max electron dispersive $\mathrm{x}$-ray spectroscopy detector (Oxford), AZTEC software.

Figure 7 shows that the interface $\mathrm{CuCr} 1 \mathrm{Zr}-\mathrm{SS} 316 \mathrm{~L}$ is free from major defects. The bonding zone shows a low amount of microporosity on the $\mathrm{CuCr} 1 \mathrm{Zr}$ side, most probably corresponding to the Kirkendall effect [22] due

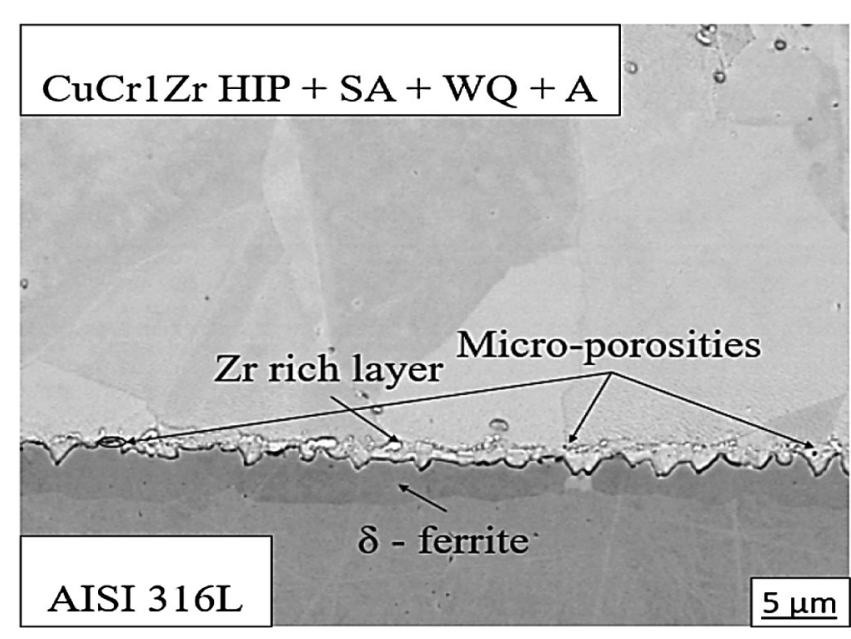

FIG. 7. SEM image at $3000 \times$ and $15 \mathrm{kV}$ accelerating voltage. A continuous $\delta$-ferrite layer is visible on the SS side, whereas microporosities due to the Kirkendall effects and $\mathrm{Zr}$ inclusions (observed also in Ref. [10]) are distinguishable on the $\mathrm{CuCr} 1 \mathrm{Zr}$ side.

to the different diffusion coefficients between the bonding materials, a first indicator that the diffusion took place.

As shown by Fig. 8, several EDX analyses of the interface $\mathrm{CuCr} 1 \mathrm{Zr}$ SS $316 \mathrm{~L}$ revealed a general trend: a few micrometers $\mathrm{Cr}$ rich and $\mathrm{Ni}$ poor layer with some diffused $\mathrm{Cu}$ is present on the steel side, whereas $\mathrm{Zr}$ rich precipitates with some diffused $\mathrm{Fe}$ are on the $\mathrm{CuCr} 1 \mathrm{Zr}$ side [23]. The darker continuous layer of about $5 \mathrm{~m}$ thickness visible on the steel side is $\delta$-ferrite. According to the Schaeffler diagram for stainless steel, nickel loss at the SS

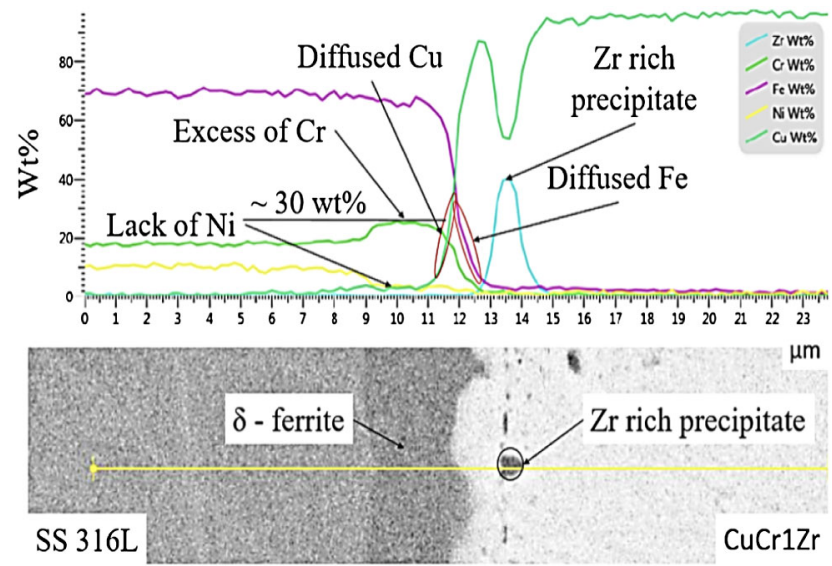

FIG. 8. EDX elemental linescans acquired at $20 \mathrm{keV}$ accelerating voltage in a direction perpendicular to the interface in order to assess the diffusion phenomena. The $\mathrm{x}$ axis represents in $\mu \mathrm{m}$ the yellow line at the bottom of the picture, and the $\mathrm{y}$ axis gives the concentration of the chemical elements along this line. On the SS 316L side, there is a clear excess of Cr up to $30 \mathrm{wt} \%$ and a lack of $\mathrm{Ni}$ with some diffused $\mathrm{Cu}$. On the $\mathrm{CuCr} 1 \mathrm{Zr}$ side, it can be distinguished a peak corresponding to a $\mathrm{Zr}$ inclusion and some diffused Fe. 


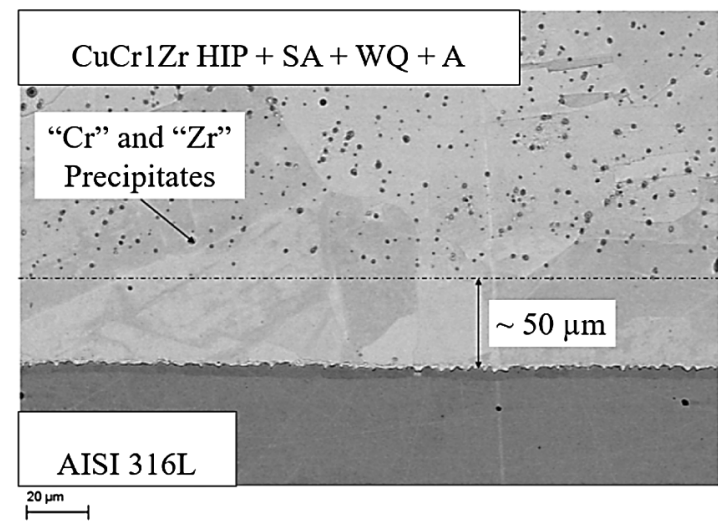

FIG. 9. SEM image $500 \times$ of the CuCr1Zr-SS 316L interface. Dark $\mathrm{Cr}$ and $\mathrm{Zr}$ precipitates consolidated during aging are visible on the $\mathrm{CuCr} 1 \mathrm{Zr}$ side.

316L/CuCr1Zr interface, $\mathrm{Cr}$ diffusion to SS 316L, plus $\mathrm{Cr}$ enrichment up to $30 \mathrm{wt} \%$ are responsible for the formation of a fully ferritic layer at the joint. Figure 9 also shows large dark $\mathrm{Cr}$ and $\mathrm{Zr}$ precipitates consolidated during the aging process which diminish in a layer of about $50 \mathrm{~m}$ close to the SS316L/CuCr1Zr interface.

Figure 10 shows an optical microscopy of the interface $\mathrm{CuCr} 1 \mathrm{Zr}-\mathrm{CuCr} 1 \mathrm{Zr}$, which appears clearly discernible, homogeneous, and without significant voids population. Interfacial grain boundaries lie in the plane of the joint.

\section{G. Thermal conductivity measurements}

Figure 11 shows the measurements of thermal conductivity, from room temperature to $300^{\circ} \mathrm{C}$, of pure copper, precipitation hardened $\mathrm{CuCr} 1 \mathrm{Zr}$, SS 316L and on samples containing their respective HIP diffusion-bonded interfaces, performed by using a NETZSCH nanoflash LFA447.

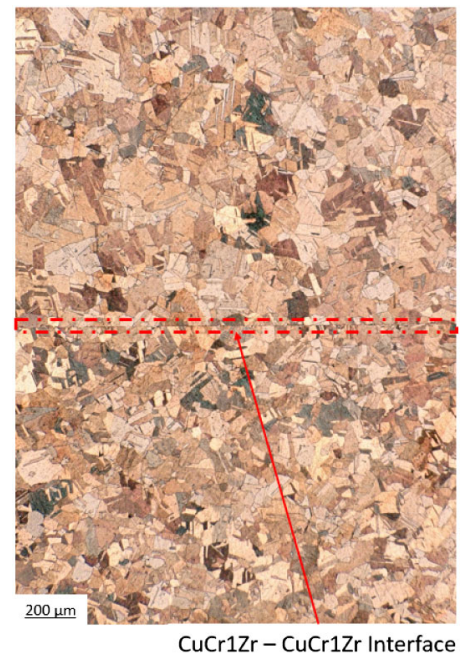

FIG. 10. Optical microscopy of a sample containing the HIP diffusion bonded $\mathrm{CuCr} 1 \mathrm{Zr}-\mathrm{CuCr} 1 \mathrm{Zr}$ interface. The surface inspected has been mechanically polished and chemically etched.

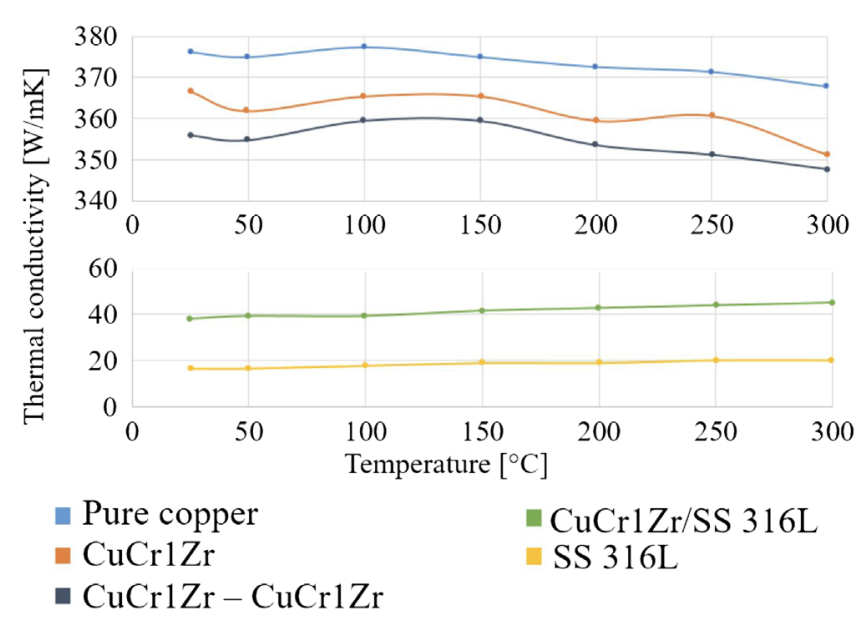

FIG. 11. Thermal conductivity measurements at the materials bulks and interfaces.

At the interface $\mathrm{CuCr} 1 \mathrm{Zr}-\mathrm{CuCr} 1 \mathrm{Zr}$ (dark blue line), the thermal conductivity, within uncertainties, is as high as that measured in the bulks of precipitation hardened $\mathrm{CuCr} 1 \mathrm{Zr}$ (orange line) and pure copper (light blue line), with values ranging between $350 \pm 10$ and $360 \pm 10 \mathrm{Wm}^{-1} \mathrm{~K}^{-1}$. Similarly, the thermal conductivity at the interface CuCr1Zr-SS 316L (green line) and the bulk of SS 316L (yellow line) are close and fall in the range between $38 \pm 1$ and $45.0 \pm 1.4 \mathrm{Wm}^{-1} \mathrm{~K}^{-1}$. These results indicated that at the HIP diffusion bonded interfaces, the values are limited by the material with the lowest thermal conductivity in the joint, however higher than the latter (see e.g. CuCr1Zr-SS 316L interface).

\section{H. Mechanical strength measurements}

Tensile tests at room temperature, according to the DIN EN ISO 6892-1:2017, of the HIP diffusion bonded interfaces were performed in order to quantify their mechanical strengths. Samples made of $\mathrm{CuCr} 1 \mathrm{Zr}$ and SS $316 \mathrm{~L}$ as well as containing the HIP diffusion bonded interfaces were prepared by electro-erosion. The initial cross section dimensions and gauge length are the following (Fig. 12): width $\left(b_{0}=2 \mathrm{~mm}\right)$, thickness $\left(a_{0}=1.5 \mathrm{~mm}\right)$, cross-sectional area $\left(S_{0}=3 \mathrm{~mm}^{2}\right)$, and gauge length $\left(L_{0}=4.6 \mathrm{~mm}\right)$.

Figure 13 shows the overall dimensions of tested tensile samples containing the $\mathrm{CuCr} 1 \mathrm{Zr}-\mathrm{CuCr} 1 \mathrm{Zr}$ and $\mathrm{CuCr} 1 \mathrm{Zr}$ SS 316L interfaces within the gauge length. The specimen is a proprietary development of IFAM-Dresden and does not comply with the proportionality specifications of DIN EN ISO 6892-1.

For the CuCr1Zr-SS 316L samples, the fracture appears to be ductile and it is not at the interface but within $\mathrm{CuCr} 1 \mathrm{Zr}$. The measured mean tensile strength of $360 \pm$ $2 \mathrm{MPa}$ is comparable with precipitation hardened $\mathrm{CuCr} 1 \mathrm{Zr}$, as it is shown by the dotted line in Fig. 14. Similarly, Fig. 15 shows the results of the tensile samples containing 


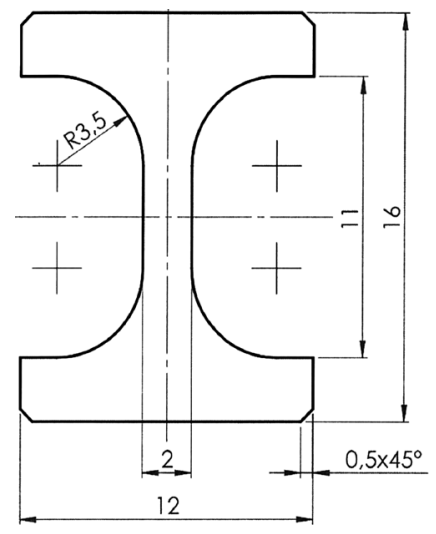

FIG. 12. Tensile specimen dimensions.

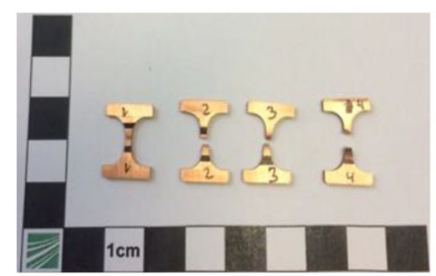

(a)

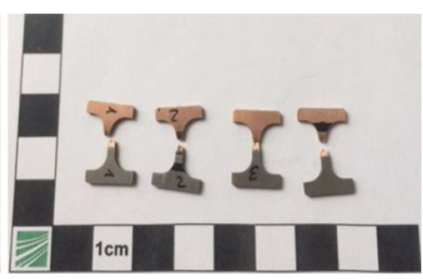

(b)
FIG. 13. Tensile samples containing (a) the $\mathrm{CuCr} 1 \mathrm{Zr}-\mathrm{CuCr} 1 \mathrm{Zr}$ interface and (b) the CuCr1Zr-SS 316L interface.

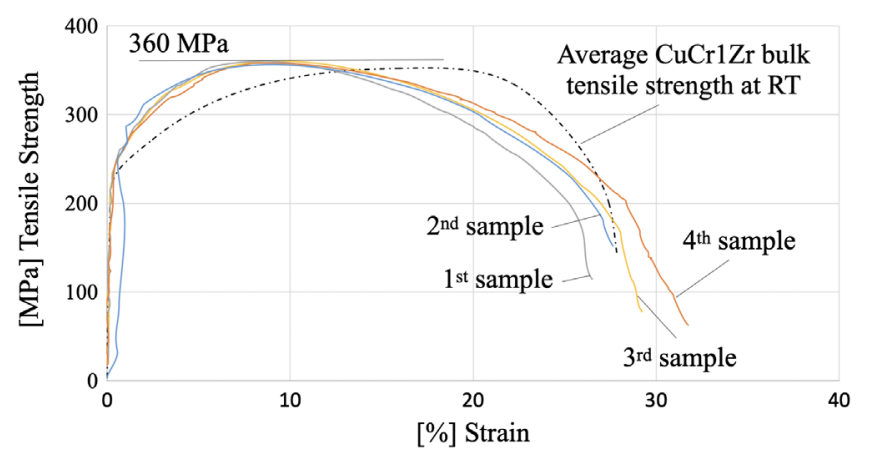

FIG. 14. Room temperature tensile stress-strain curves for $\mathrm{CuCr} 1 \mathrm{Zr}-\mathrm{SS}$ 316L specimens and bulk hardened $\mathrm{CuC} 1 \mathrm{Zr}$ as a reference.

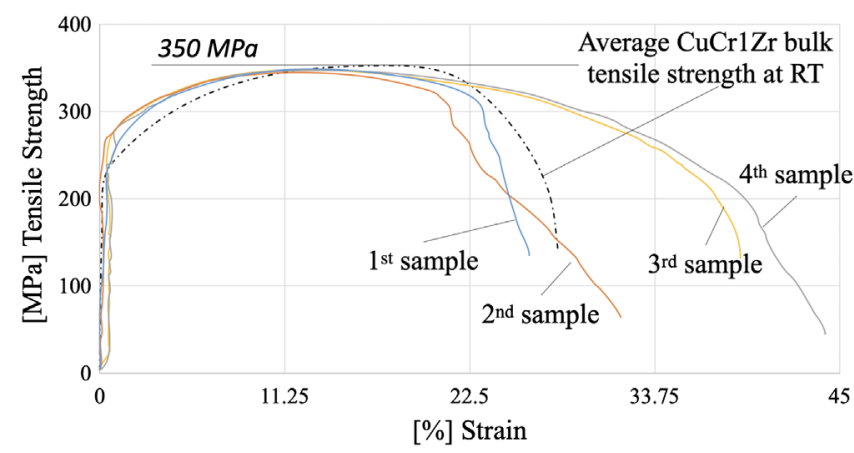

FIG. 15. Room temperature tensile stress-strain curves for $\mathrm{CuCr} 1 \mathrm{Zr}-\mathrm{CuCr} 1 \mathrm{Zr}$ specimens and bulk hardened $\mathrm{CuCr} 1 \mathrm{Zr}$.
TABLE V. Tensile strengths' statistics, average and standard deviation "s", of the specimens with the interfaces $\mathrm{CuCr} 1 \mathrm{Zr}$ / $\mathrm{CuCr} 1 \mathrm{Zr}, \mathrm{CuCr} 1 \mathrm{Zr} / \mathrm{SS}$ 316L and for specimens of $\mathrm{CuCr} 1 \mathrm{Zr}$ without interface.

\begin{tabular}{lc}
\hline \hline Samples & $R_{m}[\mathrm{MPa}]$ \\
\hline $\mathrm{CuCr} 1 \mathrm{Zr} / \mathrm{SS} \mathrm{316L}$ & $359 \pm 2$ \\
$\mathrm{CuCr} 1 \mathrm{Zr} / \mathrm{CuCr} 1 \mathrm{Zr}$ & $347 \pm 2$ \\
Bulk CuCr1Zr & $352 \pm 3$ \\
\hline \hline
\end{tabular}

the $\mathrm{CuCr} 1 \mathrm{Zr}-\mathrm{CuCr} 1 \mathrm{Zr}$ interface. The mean measured tensile strength of $348 \pm 2 \mathrm{MPa}$ is very close to the bulk precipitation hardened $\mathrm{CuCr} 1 \mathrm{Zr}$ of $352 \pm 3 \mathrm{MPa}$. The presence of a diffusion bonded interface does not seem to affect the mechanical strength, which is, instead, limited by the lowest one of the joining materials. Nevertheless, the samples containing the $\mathrm{CuCr} 1 \mathrm{Zr} / \mathrm{SS} 316 \mathrm{~L}$ interface exhibit a lower elongation at necking with respect to the bulky $\mathrm{CuCr} 1 \mathrm{Zr}$ ones. This difference is smaller for the $\mathrm{CuCr} 1 \mathrm{Zr} /$ $\mathrm{CuCr} 1 \mathrm{Zr}$ samples. However, the total elongations are comparable and in most cases close to $30 \%$. Table V summarizes the mean values of tensile strengths.

\section{Cooling performance test bench}

In order to assess the ability of the HIP manufactured prototype to evacuate the thermal power deposited in the most critical regions of the SPS internal dumps cooling plates and in the worst operational scenario, as well as to verify that the cooling performance all over the prototype was homogeneous, a dedicated test bench was designed. In order to validate the first point, the cooling plate prototype needed to be able to reach a steady state with an average temperature well below $300^{\circ} \mathrm{C}$. Indeed, as Fig. 16 shows, starting from $300^{\circ} \mathrm{C}$, the measured yield strength of precipitation hardened $\mathrm{CuCr} 1 \mathrm{Zr}$ becomes too low for a robust and reliable operation of the SPS internal dump.

As for the homogeneity of the cooling performance, the amount of power evacuated by the two tubes as well as the

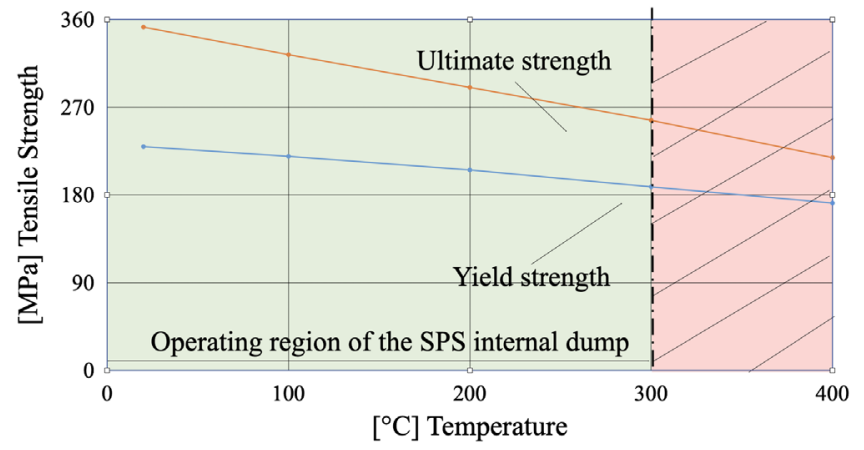

FIG. 16. Yield and ultimate strength of precipitation hardened $\mathrm{CuCr} 1 \mathrm{Zr}$ from room temperature to $400{ }^{\circ} \mathrm{C}$. Every $\mathrm{CuCr} 1 \mathrm{Zr}$ component of the SPS internal dump shall operate at a temperature always below the limit of $300^{\circ} \mathrm{C}$. 


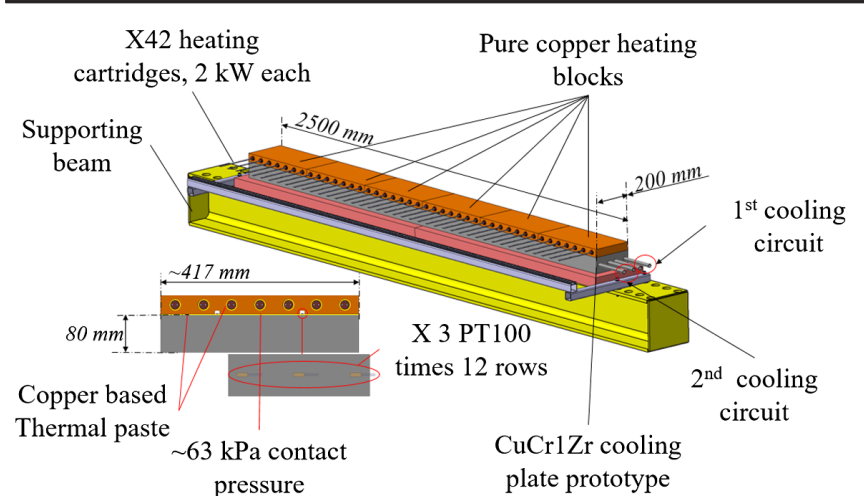

FIG. 17. Components of the cooling test bench and the respective configuration.

cooling rates measured at different locations of the prototype plate shall be the same within the measurement errors.

\section{Experimental setup}

The test bench is made of four main systems/parts: the heating and cooling systems, the monitoring system, and the part tested. The heating system reproduces the thermal power deposited by the particle beam. The cooling system extracts this power in the same way the actual system would operate on the dump's cooling plates in operation, and finally the monitoring system gives feedback about the temperatures and the inlet/outlet flow rates of the part being tested. Figure 17 shows the main test bench components used to assess the cooling performance of the HIP manufactured cooling plate prototype. Specifically, the thermal power deposited by the particle beam is reproduced by six oxygen-free high thermal conductivity copper heating blocks. Every heating block has seven electrical heating cartridges $2 \mathrm{~kW}$ each, for a total power of $84 \mathrm{~kW}$.

In order to improve the heat flow, a copper-based hightemperature lubricant with very good thermal conductivity (ORAPI TM900S) couples the heating cartridges with the heating blocks and these latter with the cooling plate prototype. The heating blocks are pressed against the prototype plate establishing an average calculated contact pressure of about $63 \mathrm{kPa}$. The temperature distribution interface at the heating blocks-cooling plate interface is monitored by 36 PT100s sensors. The whole assembly is enclosed within insulating fiberglass plates $50 \mathrm{~mm}$ thick.

The prototype plate is equipped with two cooling circuits shown in Fig. 17, following the same design of the SPS internal dump cooling loop. Figure 18 shows the piping and instrumentation diagram (P\&ID) of the circuits. An inlet flow rate of $5 \mathrm{~m}^{3} / \mathrm{h}$ and 7 bar of demineralized water is equally split in the two circuits of the prototype. At the inlet, the temperature is kept constant at $27^{\circ} \mathrm{C}$, and it is monitored by a temperature indicator and transmitter installed directly in the line. Flow rates and temperatures at the outlet circuits are measured by two types of

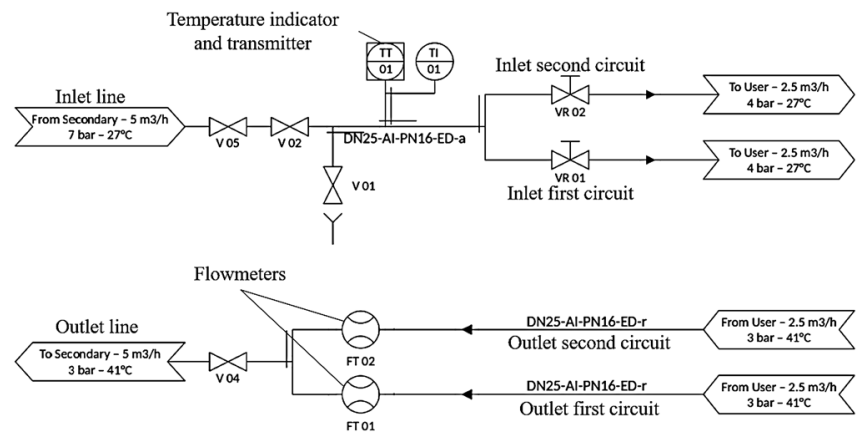

FIG. 18. P\&ID cooling performance test bench.

flowmeters FC 100 LQ from Flow Vision. The electrical heating cartridges, the PT100 temperature sensors, the flowmeters, and the inlet temperature transmitter are all connected to a programmable logic controller and controlled via dedicated software.

\section{Test procedure}

Every test was carried out by the following steps: (1) The cooling circuits are activated. (2) The thermal power is gradually increased until the testing level is reached. (3) The test bench is left to reach the steady state where the average cooling plate temperature and the cooling circuit's inlet and outlet temperatures are recorded. (4) The power is shut down and the cooling rates at different points of the plates are measured.

\section{Results}

The highest tested thermal power was $84 \mathrm{~kW}$, which is roughly equivalent to the maximum expected average power deposited in the most critical of the four plates composing the TIDVG\#5. Figure 19 shows the increase of average temperature of all the PT100s sensors over time, from the beginning up to the steady state. Given the cooling system in place and the amount of power tested, it took about $32 \mathrm{~min}$ to reach the steady state at an average temperature of $136{ }^{\circ} \mathrm{C}$. Figure 20 shows the temperature over time at the inlet and outlets of the cooling circuits. At

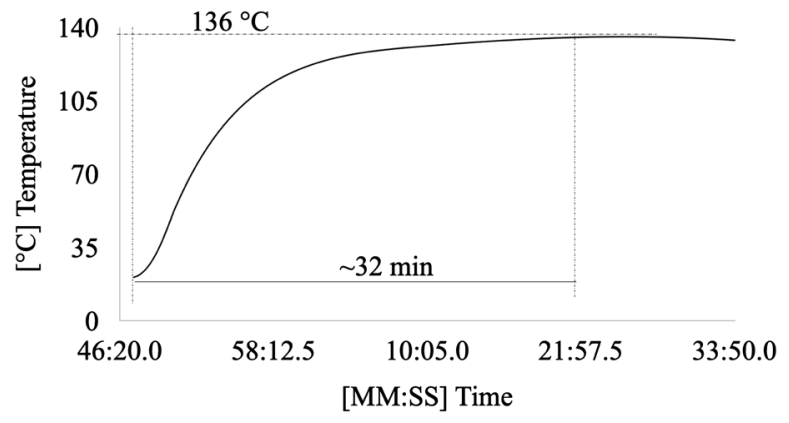

FIG. 19. Average PT100s temperature over time to steady state of the heating phase. 


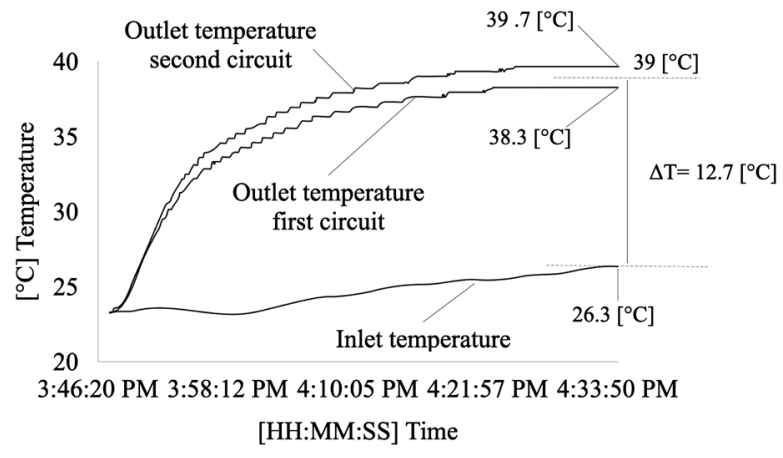

FIG. 20. Inlet and outlets water temperature versus time during heating phase at $84 \mathrm{~kW}$.

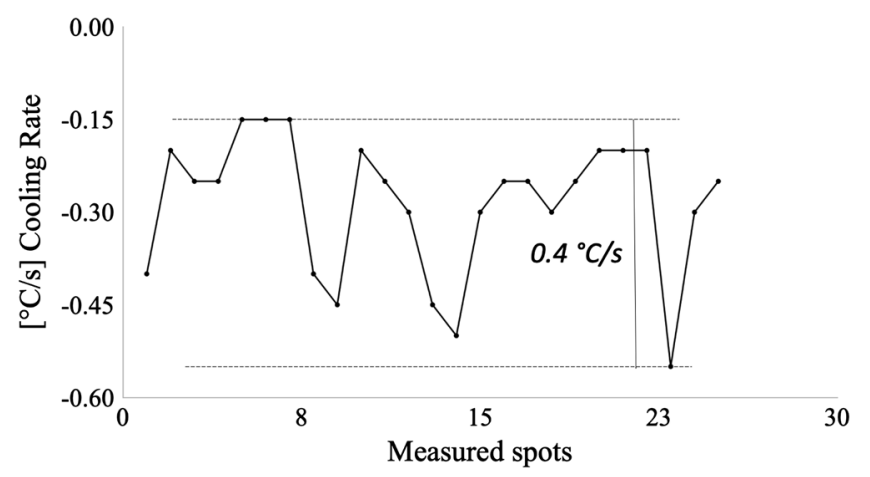

FIG. 21. Maximum cooling rates measured in some points of the prototypes surface.

steady state condition, this information along with the flow rates allows to calculate the thermal power extracted by the circuits. The outlet temperature difference of lessthan $2{ }^{\circ} \mathrm{C}$ suggests that the two circuits behave in the same way and evacuate a similar amount of thermal power, precisely, 39 and $35 \mathrm{~kW}$, summing up to $74 \mathrm{~kW}$. Around $10 \mathrm{~kW}$ are lost due to the not perfect insulation of the test bench. When the power is shut down and the cooling plate temperature starts decreasing, the cooling rates in several points of the prototype were measured. Figure 21 shows that the maximum difference between the cooling rates is below $0.5^{\circ} \mathrm{C} / \mathrm{s}$. This result, along with the similar thermal power evacuated, is a good indicator that the cooling performance of the prototype is homogeneous.

\section{DISCUSSION}

The objective of the present study was to carry out a complete characterization of the $\mathrm{CuCr} 1 \mathrm{Zr}-\mathrm{CuCr} 1 \mathrm{Zr}$ and CuCr1Zr-SS 316L HIP diffusion bonded interfaces and to assess the cooling performance of the cooling plate prototype under the worst operational scenario of the SPS beam internal dump. In its most narrow definition, diffusion bonding is a process that produces solid-state coalescence between two clean surfaces. The process is composed of a three-stage metallurgical phase [24]: (1) The contact area grows to a large fraction of the joint area by localized deformation of the contacting surface asperities. At the completion of this stage, the interface boundary is no longer a planar interface but consists of voids separated by areas of intimate contact. In these areas of contact, the joint becomes equivalent to a grain boundary between the grains on each surface. (2) All of the voids in the joints shrink and most are eliminated. The interfacial grain boundary migrates out of the plane of the joint to a lower-energy equilibrium. Bonding could be considered essentially complete after this stage. (3) Diffusional processes caused the shrinkage and elimination of voids; now, the only possible path is through the volume of the grains themselves.

For the CuCr1Zr-SS 316L interface, there was a good contact of the surfaces and two diffusional phenomena were also observed in literature [5]: (1) Low amount of microporosity on the $\mathrm{CuCr} 1 \mathrm{Zr}$ side, most probably due to the Kirkendall effect. (2) The Cr-rich and Ni-poor diffusion layer with some diffused $\mathrm{Cu}$ on the SS 316L side and $\mathrm{Cr}$ - and $\mathrm{Zr}$-rich inclusions with some diffused $\mathrm{Fe}$ on the $\mathrm{CuCr} 1 \mathrm{Zr}$ side.

The $\mathrm{CuCr} 1 \mathrm{Zr}-\mathrm{CuCr} 1 \mathrm{Zr}$ interface was clearly discernible, homogeneous, and without significant voids population. For both interfaces, the interfacial grain boundaries remained in the plane of the joint; therefore, the diffusion bonding cannot be considered fully complete according to the above definition. Nevertheless, the measurements of thermal conductivity and mechanical strength, for the CuCr1Zr-SS 316L interface, showed values limited by the SS $316 \mathrm{~L}$ and comparable to its bulk, whereas for the $\mathrm{CuCr} 1 \mathrm{Zr}-\mathrm{CuCr} 1 \mathrm{Zr}$ interface, the values were comparable to the bulk of precipitation hardened $\mathrm{CuCr} 1 \mathrm{Zr}$. For these reasons, it can be concluded that the diffusion bonding reached advanced stage (phase 2). The data obtained from the test bench showed that the manufactured real size prototype is well capable of withstanding the thermal power that the most critical of the SPS dumps cooling plates would undergo in the worst operational scenario. Finally, the homogeneity of the cooling performance suggests that the HIP diffusion bonding process, for the corresponding interfaces all over the prototype plate, is homogeneous.

\section{CONCLUSIONS}

The future CERN SPS internal dump, TIDVG\#5, will have to cope with higher beam intensities and repetition dumping rates starting from 2021. The maximum average thermal power carried by the beam can be as high as approximately $270 \mathrm{~kW}$ and about $90 \%$ of it is absorbed by the dump and shall be evacuated by the cooling plates. Their cooling performance is, therefore, crucial. Diffusion bonding of stainless steel 316L and precipitation hardened $\mathrm{CuCr} 1 \mathrm{Zr}$ by HIPing was thoroughly investigated as a manufacturing technique for the dumps cooling plates to reduce interfacial thermal resistance between the different components. Microstructural analyses and measurements 
of thermal conductivity and mechanical strength suggest that diffusion bonding at the interfaces CuCr1Zr-SS316L and $\mathrm{CuCr} 1 \mathrm{Zr}-\mathrm{CuCr} 1 \mathrm{Zr}$ reached an advanced stage. Moreover, a test bench allowed to measure the cooling performance of the real size prototype with the worst operational scenario and proved that the cooling performance is uniform and the manufacturing technique can be used for the real cooling plates of the future SPS internal dump. In conclusion, the present work opens up the way for further investigations on the exploitability of this technique for other challenging cooling applications in the field of high energy physics.

[1] S. Pianese et al., Design of the future high energy beam dump for the CERN SPS, in Proceedings of the 9th International Particle Accelerator Conference (IPAC18), Vancouver, Canada (JACoW Publishing, Geneva, Switzerland, 2018), pp. 2612-2615, WEPMG004, https://doi.org/ 10.18429/JACoW-IPAC2018-WEPMG004.

[2] J. Coupard, H. Damerau, A. Funken, R. Garoby, S. Gilardoni, B. Goddard, K. Hanke, A. Lombardi, D. Manglunki, M. Meddahi, B. Mikulec, G. Rumolo, E. Shaposhnikova, and M. Vretenar, LHC injector upgrade, CERN, Geneva, Technical Design Report No. CERNACC-2014-0337, 2014, https://cds.cern.ch/record/ 1976692.

[3] P. Rios-Rodriguez et al., Analysis and operational feedback of the new design of high energy beam dump in the CERN SPS, in Proceedings of the 8th International Particle Accelerator Conference (IPAC17), Copenhagen, Denmark (JACoW Publishing, Geneva, Switzerland, 2017), pp. 3524-3527, WEPVA110, https://doi.org/ 10.18429/JACoW-IPAC2017-WEPVA110.

[4] M. Ross, The millenium dump TIDVG commissioningApril 2000, CERN, Geneva, Technical Report No. SLNote-2000-050-BT, 2000, https://cds.cern.ch/record/ 702618.

[5] G. L. Marois et al., Hip'ing of copper alloys to stainless steel, J. Nucl. Mater. 233, 927 (1996).

[6] H. Atkinson and S. Davies, Fundamental aspects of hot isostatic pressing: An overview, Metall. Mater. Trans. A 31, 2981 (2000).

[7] A. Y. Kumar et al., The effects of hot isostatic pressing on parts fabricated by binder jetting additive manufacturing, Addit. Manuf. 24, 115 (2018).

[8] J. Wu et al., Effect of hot isostatic pressing loading route on microstructure and mechanical properties of powder metallurgy $\mathrm{Ti}_{2} \mathrm{AlNb}$ alloys, J. Mater. Sci. Technol. 33, 172 (2017).

[9] J. B. Descarrega, M. Calviani, T. Hutsch et al., Application of hot isostatic pressing (HIP) technology to diffusion bond refractory metals for proton beam targets and absorbers at CERN, Mater. Des. Process. Commun. 2, e101 (2020).

[10] N. Ordás, F. Samaniego, I. Iturriza, A. Gómez, C. Escudero, A. I. Fernández-Calvo, I. Cobo, S. Banetta, S. Heikkinen, and T. Cicero, Mechanical and microstructural characterization of HIP joints of a simplified prototype of the ITER NHF first wall panel, Fusion Eng. Des. 124, 999 (2017).

[11] S. Makimura et al., Present status of construction for the muon target in J-PARC, Nucl. Instrum. Methods Phys. Res., Sect. A 600, 146 (2009).

[12] S. Tähtinen, A. Laukkanen, and B. Singh, Investigations of copper to stainless steel joints, Fusion Eng. Des. 56-57, 391 (2001).

[13] S. Tähtinen, A. Laukkanen, B. Singh, and P. Toft, Properties of copperstainless steel hip joints before and after neutron irradiation, J. Nucl. Mater. 307-311, 1547 (2002).

[14] S. Goods and J. Puskar, Solid state bonding of CuCrZr to 3161 stainless steel for ITER applications, Fusion Eng. Des. 86, 1634 (2011).

[15] G. Romagnoli et al., Engineering design and prototyping of the new LIU PS internal beam dumps, in Proceedings of the 9th International Particle Accelerator Conference (IPAC18), Vancouver, Canada (JACoW Publishing, Geneva, Switzerland, 2018), pp. 2600-2603, WEPMG001, https://doi.org/10.18429/JACoW-IPAC2018-WEPMG001.

[16] E. L. Sola, M. Calviani et al., Beam impact tests of a prototype target for the beam dump facility at CERN: Experimental setup and preliminary analysis of the online results, Phys. Rev. Accel. Beams 22, 123001 (2019).

[17] R. Catherall, T.Giles, and G. Neyens, Exploiting the potential of ISOLDE at CERN (the EPIC project), in Proceedings of the 10th International Particle Accelerator Conference (IPAC19), Melbourne, Australia (2019), pp. 3706-3708, THPGW053, http://accelconf.web.cern .ch/ipac2019/papers/thpgw053.pdf.

[18] M. J. Shirakata, H. Kuboki, and J. Takano, Radiation design of new $30 \mathrm{kw}$ beam dump of J-PARC main ring, in Proceedings of the 10th International Particle Accelerator Conference (IPAC19), Melbourne, Australia (2019), pp. 2005-2008, TUPTS032, http://accelconf.web .cern.ch/ipac2019/papers/tupts032.pdf.

[19] V. Lebedev, The PIP-II reference design report, Fermi National Accelerator Laboratory, Technical Report, 2015, https://lss.fnal.gov/archive/design/fermilab-design-201501.pdf.

[20] A. D. Ivanov, A. K. Nikolaev, G. M. Kalinin, and M. E. Rodin, Effects of heat treatments on the properties of CuCrZr alloys, J. Nucl. Mater. 307-311, 673 (2002).

[21] U. Holzwarth, H. Stamm, M. Pisoni, A. Volcan, and R. Scholz, The recovery of tensile properties of $\mathrm{CuCrZr}$ alloy after hot isostatic pressing, Fusion Eng. Des. 51-52, 111 (2000).

[22] B. Pieraggi, in Developments in High Temperature Corrosion and Protection of Materials, Metal and Surface Engineering (Woodhead Publishing, 2008), Chap. 2, pp. 9-35, diffusion and solid state reactions.

[23] F. Fagnoni, J. B. Descarrega, and E. R. Castro, Characterization of diffusion bonded $\mathrm{CuCr} 1 \mathrm{Zr}-\mathrm{CuCr} 1 \mathrm{Zr}$ and $\mathrm{CuCr} 1 \mathrm{Zr}$-steel interfaces for PS dump prototype, CERN, Geneva, EDMS document: 2136203, 2018.

[24] K. Ferjutz and J. R. Davis, in ASM Handbook: Welding, Brazing, and Solderings (ASM International, Materials Parks, OH, 1993), Vol. 6. 